\title{
Insetos que visitam o "Cupuaçu", Theobroma grandifilorum (Willd. ex Spreng.) Schum. (Sterculiaceae), e índice de ataque nas folhas
}

\author{
Marlene Freitas da Silva $\left(^{*}\right)$
}

\begin{abstract}
Resumo
O alto valor comercial de Theobroma grandiflorum (Willd. ex Spreng.) Schum., com habitat natural na Amazônia, levou a autora a fazer algumas observações quanto ao ataque sofrido pela planta, principalmente em suas partes mais jovens, prejudicando assim não só o seu desenvolvimento como também os órgãos de reprodução, por parte de alguns insetos que visitam a espécie. Algumas observações sobre a polinização das flores foram também efetuadas, estando possivelmente envolvida neste particular a abelha Ptilotrigona lurida (Smith) da família Apidae.
\end{abstract}

\section{INTRODUÇÃo}

Theobroma grandiflorum, uma espécie cujos frutos são bastante apreciados em nossa região, principalmente para a confecção de doces, sorvetes, refrescos, etc... e até de valor industrial, é ramiflora e nela se observa um grande número de insetos cujo relacionamento com a planta nos fez levantar as seguintes especulações :

- "Até que ponto estes insetos têm suas atividades relacionadas com a referida planta?"

-. "Possui a espécie nectários extra-florais?"

- As formigas nela presentes têm suas ati. vidades relacionadas com a proteção das flores aos predadores?"

- "Nos indivíduos sem flores a atividade das formigas é igual, menor ou maior do que nas plantas com flores?"

- "Qual ou quais os insetos que atacam as folhas, e qual o índice de ataque observado ?"

- "Qual o possível polinizador das flores, já que a espécie possui uma estrutura floral bastante complexa?"

Cuatrecasas (1964) faz suscintos comentários sobre o transporte do pólen pelo vento, e de alguns experimentos efetuados por outros pesquisadores como Harland, Stahel, Posnette, Saunders, Cope, Uzel, Jones e Pound, os quais demonstraram que diversas espécies de moscas, formigas, afídios, etc... estão envolvidos na polinização de algumas espécies deste mesmo gênero.

\section{MATERIAL E MÉTODO}

O material estudado é encontrado na Reserva Florestal Ducke (INPA), no km 26 da estrada Manaus-Itacoatiara, e o método desenvolvido constou dos seguintes ítens:

a. Seleção dos indivíduos (2 com flores e 2 sem flores), para a observação da presença dos insetos e coleta de material para identificação;

b. Observação da ação dos insetos na planta, como: visita às flores, a nectários extraflorais ou às folhas;

c. Identificação de morfo-espécies de insetos no laboratório, e remessa de alguns exem. plares a especialistas para identificação;

d. Cálculos da área total e de ataque nas folhas (comparação feita entre as árvores com flores e as sem flores), existentes no mesmo local, sob as mesmas condições ambientais;

e. Observação e coleta dos possíveis herbívoros e polinizadores.

As observações foram efetuadas em dois horários - pela manhã e à tarde (das 7 às 9 horas, e das 14 às 15 horas), a fim de verificar. mos uma possível variação na ação ou mesmo se diferentes espécies de insetos agiam em horários diferentes.

Para o cálculo da área total das folhas e área atacada das folhas, fizemos coleta de folhas ao acaso - isto porque a espécie apresenta uma grande variação no tamanho das

(*) - Instituto Nacional de Pesquisas da Amazônia, Manaus. 
folhas - de cinco (5) folhas de cada indivíduo considerando duas (2) plantas com flores e duas (2) sem flores, e utilizamos para o cálculo em geral, uma escala de papel transparente, quadriculado, em que cada quadrado menor tinha um lado igual a $0,5 \mathrm{~cm}$ e conseqüentemente uma área total de valor igual a $0,25 \mathrm{~cm}^{2}$. Esta escala era colocada sobre a folha e por transparência contados os quadrinhos abrangidos (tanto para o cálculo da área total da folha, como para o da área atacada), e efetuados os cálculos finais.
As abelhas foram entregues ao Setor de Entomologia do INPA onde estão registradas sob o número - INPA 0082, e identificadas pelo Sr. Joäo Camargo, do Departamento de Genética da Fac. Medicina de Ribeirão Preto. U.S.P.

\section{Resultados}

Os insetos e larva observados nas diversas partes dos indivíduos em horários diferentes são apresentados na Tabela 1.

Tabela 1 - Insetos observados em Theobroma grandiflorum

A. Individuos com flores.

\begin{tabular}{|c|c|c|}
\hline Árv. $n$. & $\begin{array}{c}\text { Inseto ou larva } \\
\text { (Ord. Fam. ou Gên.) }\end{array}$ & Local da planta observado \\
\hline 1 & $\begin{array}{l}\text { HYMENOPTERA } \\
\text { Formicidae: }(++) \\
\text { Camponotus } \mathrm{sp} \\
\text { Crematogaster sp } \\
\text { Apidae: }(+) \\
\text { Tetragona clavipes } \\
\text { Ptilotrigona lurida } \\
\text { ORTHOPTERA } \\
\text { Acrididae: }(++) \\
\text { Cononphaius sp } \\
\text { HOMOPTERA } \\
\text { Membracidae: }(++) \\
\text { "pulgão" }\end{array}$ & $\begin{array}{l}\text { Ramos jovens, extremidades dos ramos cálice da flor, } \\
\text { botões florais, e pecílos. } \\
\text { Além dos locais acima citados, mais frequentemente so- } \\
\text { bre as folhas. } \\
\text { Sobrevoando as flores, algumas até pousando sobre } \\
\text { elas, porém muito ariscas. } \\
\text { Flores já abertas; perfurando a parte côncava da pétala, } \\
\text { afim de retirar o pólen. } \\
\text { Sobre as folhas. } \\
\text { Aglomerados nos ramos e outras partes jovens da plan- } \\
\text { ta, juntamente com as formigas. }\end{array}$ \\
\hline il & $\begin{array}{l}\text { HYMENOPTERA } \\
\text { Formicidae: }(++) \\
\text { Crematogaster } \mathrm{sp} \\
\text { Camponotus sp } \\
\text { Apidae: }(+) \\
\text { Tetragona clavipes } \\
\text { Ptilotrigona lurida } \\
\text { ORTHOPTERA } \\
\text { Acrididae: } \\
\text { Conocephalus sp }(++) \\
\text { Phasmidae: }(+) \\
\text { (ninfa) } \\
\text { LEPIDOPTERA } \\
\text { (estágio larvar) }(++)\end{array}$ & $\begin{array}{l}\text { Nos mesmos locais antes citados. } \\
\text { Idem... } \\
\text { Idem... } \\
\text { Idem... } \\
\text { Sobre folhas adultas. } \\
\text { Atacando intensamente as folhas jovens. }\end{array}$ \\
\hline
\end{tabular}


B. Individuos sem flores.

\begin{tabular}{|c|c|c|}
\hline Árv. $n$. & $\begin{array}{c}\text { Inseto ou larva } \\
\text { (Ord. Fam. ou Gên.) }\end{array}$ & Local da planta observado \\
\hline II & $\begin{array}{l}\text { HYMENOPTERA } \\
\text { Formicidae: }(++) \\
\text { Crematogaster sp } \\
\text { Camponotus sp } \\
\text { HOMOPTERA } \\
\text { Membracidae } \\
\text { "pulgão" }(++) \\
\text { LEPIDOPTERA } \\
\text { (estágio larvar) }(++) \\
\text { ORTHOPTERA } \\
\text { Phasmidae: }(+++) \\
\text { DIPTERA } \\
\text { Micropezideae }(+) \\
\text { HYMENOPTERA } \\
\text { Formicidae: }(++) \\
\text { Crematogaster sp } \\
\text { Camponotus sp } \\
\text { HOMOPTERA } \\
\text { Membracideae } \\
\text { "pulgão" }(++)\end{array}$ & $\begin{array}{l}\text { Aglomeradas nas partes jovens da planta juntamente } \\
\text { com o pulgâo". } \\
\text { Idem... } \\
\text { Idem... }\end{array}$ \\
\hline
\end{tabular}

$(+)$ - Observado apenas no horário da manhă.

$(++)$ - Observado pela manhā e à tarde.

$(+++)$-. Observado apenas no horário da tarde.

Os resultados para a área total e de ataque de cada folha, de cada indivíduo, são mostrados na Tabela 2, assim como o percentual de ataque por folha, e média de ataque nas folhas da espécie considerada.

Tabela 2. Área total e área atacada das folhas, percentual e média de ataque nas folhas de Theobroma grandiflorum.

A. Individuos com flores

\begin{tabular}{|c|c|c|c|c|c|c|}
\hline Árv. N.॰ & $\begin{array}{l}\text { Folha } \\
\text { N.० }\end{array}$ & $\begin{array}{l}\text { Area total } \\
\left(\mathrm{cm}^{2}\right)\end{array}$ & $\begin{array}{c}\text { Area de Ataque } \\
\left(\mathrm{cm}^{2}\right)\end{array}$ & $\begin{array}{l}\% \text { de } \\
\text { Ataque }\end{array}$ & $\begin{array}{l}\text { Ataque } \\
(\overline{\mathrm{X}})\end{array}$ & $\mathrm{s}$ \\
\hline 1 & $\begin{array}{l}01 \\
02 \\
03 \\
04 \\
05\end{array}$ & $\begin{array}{l}178,50 \\
201,55 \\
124,75 \\
573,25 \\
472,00\end{array}$ & $\begin{array}{r}1,38 \\
3,13 \\
6,88 \\
34,50 \\
23,63\end{array}$ & $\begin{array}{l}0,77 \\
1,55 \\
5,52 \\
6,02 \\
5,01\end{array}$ & 3,77 & 2,428 \\
\hline $\begin{array}{l}11 \\
=\end{array}$ & $\begin{array}{l}01 \\
02 \\
03 \\
04 \\
05\end{array}$ & $\begin{array}{l}282,75 \\
221,25 \\
219,25 \\
310,25 \\
161,75\end{array}$ & $\begin{array}{r}4,38 \\
4,63 \\
21,13 \\
28,25 \\
8,88\end{array}$ & $\begin{array}{l}1,55 \\
2,09 \\
9,64 \\
9,11 \\
5,49\end{array}$ & 5,58 & 3,787 \\
\hline
\end{tabular}


B. Individuos sem fiores

\begin{tabular}{|c|c|c|c|c|c|c|}
\hline Árv. N.॰ & $\begin{array}{l}\text { Folha } \\
\text { N.॰ }\end{array}$ & $\begin{array}{l}\text { Area total } \\
\left(\mathrm{cm}^{2}\right)\end{array}$ & $\begin{array}{l}\text { Área de Ataque } \\
\qquad\left(\mathrm{cm}^{2}\right)\end{array}$ & $\begin{array}{l}\% \text { de } \\
\text { Ataque }\end{array}$ & $\begin{array}{l}\text { Ataque } \\
(\overline{\mathrm{X}})\end{array}$ & $\mathrm{s}$ \\
\hline i & $\begin{array}{l}01 \\
02 \\
03 \\
04 \\
05\end{array}$ & $\begin{array}{l}203,75 \\
244,25 \\
353,00 \\
497,75 \\
325,25\end{array}$ & $\begin{array}{r}1,50 \\
9,88 \\
16,63 \\
9,25 \\
6,25\end{array}$ & $\begin{array}{l}0,74 \\
4,05 \\
4,71 \\
3,11 \\
1,92\end{array}$ & 2,91 & 1,602 \\
\hline 11 & $\begin{array}{l}01 \\
02 \\
03 \\
04 \\
05\end{array}$ & $\begin{array}{l}360,75 \\
236,50 \\
284,25 \\
162,50 \\
195,25\end{array}$ & $\begin{array}{r}10,50 \\
3,00 \\
8,75 \\
15,00 \\
11,50\end{array}$ & $\begin{array}{l}2,91 \\
1,27 \\
3,08 \\
9,23 \\
5,89\end{array}$ & 4,48 & 3,134 \\
\hline
\end{tabular}

\section{DISCUSSÃ̃ E CONCLUSÃO}

A análise em conjunto das atividades dos insetos nas plantas nos horários observados. demonstrou apenas uma variação quantitativa de alguns deles, como Orthopteros, que pela manhã eram em maior número, e ausência total de abelhas no horário da tarde.

A planta não possui nectários extra-florais e, sim, os ramos jovens, a extremidade dos ramos adultos, pecíolos, parte externa das flores (cálice) e botões florais, totalmente recobertos por um indumento lanoso, ferrugíneo, que parece servir de alimento às formigas dos gêneros Crematogaster sp. e Camponotus sp., e ainda ao pulgão da familia Membracideae, todos de espécies desconhecidas, que convi. vem harmoniosamente no mesmo local. As formigas utilizam os ramos adultos apenas como passagem, para alcançarem as partes mais jovens da planta, onde juntamente com os "pulgões", formam aglomerados, permanecendo aí imóveis enquanto se alimentam.

Como teste de permanência apenas nos locais recobertos por tal indumento ferrugíneo, com o auxílio de um canivete retiramos este indumento de diferentes partes de diferentes indivíduos e como resultado observamos que as formigas passaram a evitar aquela região agora glabra, simplesmente contornando-a ou transpondo-a.

A atividade de tais formigas foi também notada tanto nos indivíduos com flores como naqueles sem flores, daí concluirmos que a presença das mesmas não está relacionada com a proteção das flores aos predadores, pelo menos diretamente, considerando-se as médias de ataque muito próximas, tanto nos individuos com flores como naqueles sem flores.

Pelo tipo de perfuração nas folhas e presença comprovada com coleta de material entomológico, concluimos que o ataque é efetuado por insetos da Ordem Orthoptera predadores de folhas adultas, possivelmente, e larvas da Ordem Lepidoptera parasitas de folhas jovens. Para esta última, fizemos um teste de preferência em laboratório colocando-a em uma placa de Petri juntamente com fragmentos de folhas jovens e adultas, obtendo-se comc resultado $-100 \%$ de ingestão da folha jovem e apenas vestígios nos fragmentos da folho adulta.

Por outro lado, comparativamente, a média de ataque nos indivíduos com flores é maior do que naqueles sem flores. Se isto está relacionado com a flor, podemos atribuir o fato à atração que elas exercem sobre alguns insetos, ou ainda de insetos que são atraídos por outros. (Gráfico 1).

Quanto às flores, estas apresentam uma estrutura particularmente interessante: as pétalas, em número de cinco (5), têm a base cuculada ou côncava (Fig. 1a), amarelo-claro, cobrindo totalmente as anteras, mantendo assim o pólen longe de contato com o gineceu, que por sua vez se encontra no interior do tubo formado pela soldadura parcial dos estames e estaminoides. "Qual seria então o inseto cu como faria ele para polinizar esta flor?". 


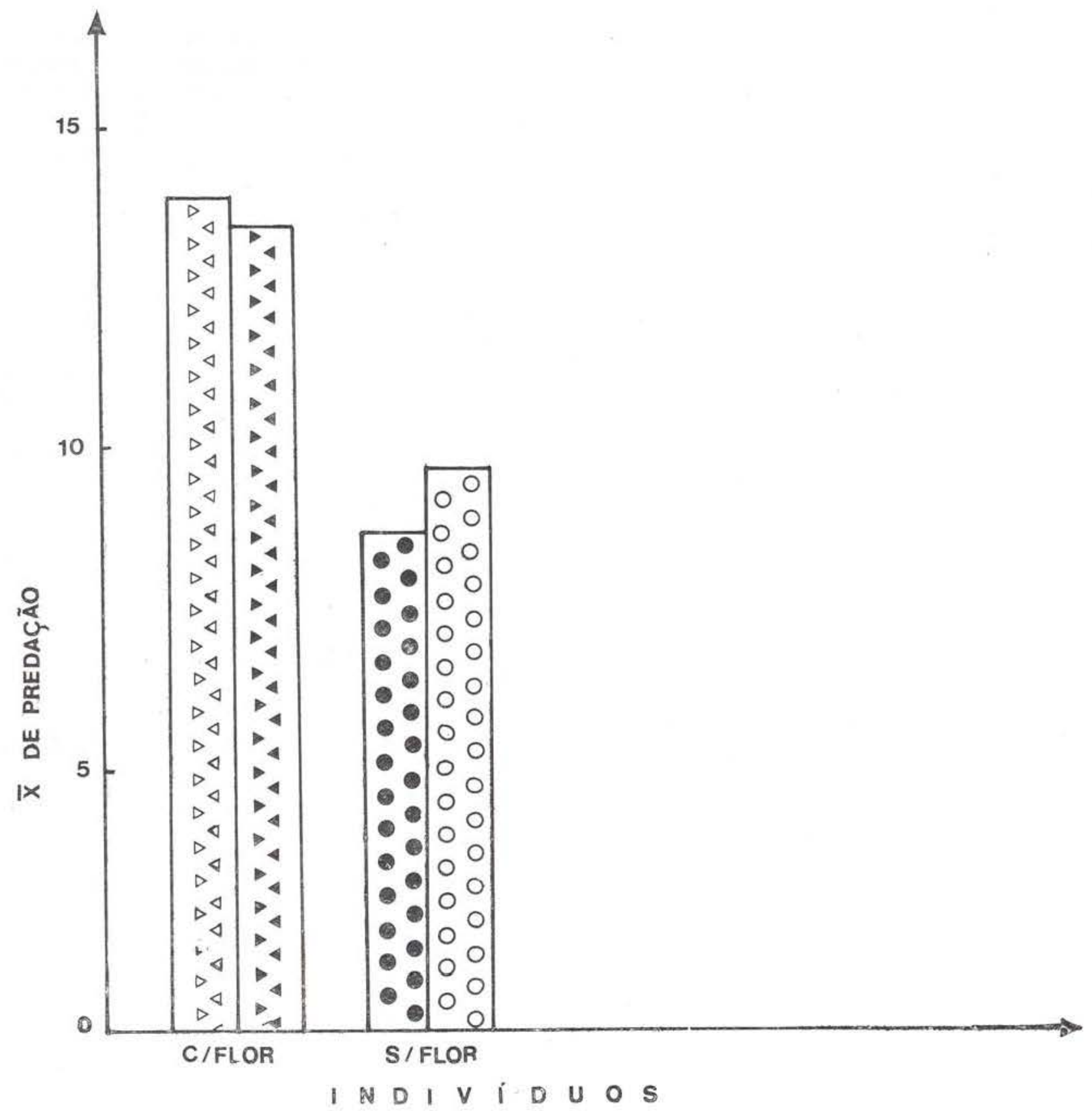

Gráfico 1 - Gráfico comparativo das médias de ataque entre os indivíduos com flores e os sem flores.

Nossas observações permitiram apenas constatar a atividade da abelha Tetragona clavipes (Fabricius), (Apidae), que simplesmente perfurava a parte côncava da pétala onde estão resquardadas as anteras (Fig. $1-B$ ), para dai retirar o pólen. No entanto, não podemos afirmar ser esta abelha responsável pela polinização da flor por diversas razões : a. O órgão feminino da flor está disposto estratégicamente fora de qualquer contato com os estames, isolado dentro de um tubo constituído pelo androceu. Aparentemente, esta abelha era apenas uma "ladra de pólen";

b. Foi observado no local um outro tipo de abelha muito arisca que não permi- 


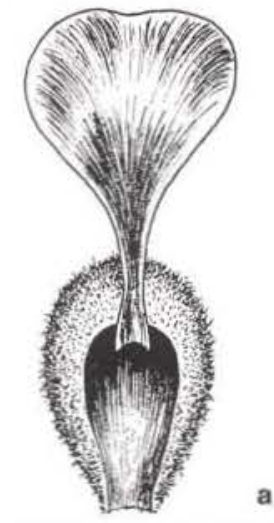

$5 \times$

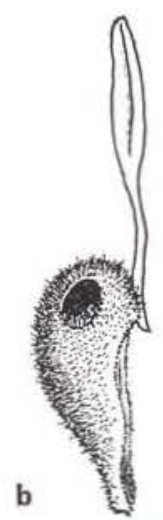

Fig. 1 - Pétala isolada de Theobroma grandiflorum. a - pétala vista de frente; $\mathbf{b}$ - pétala de lado, mostrando o local perfurado.

tia aproximação, para melhores observações, a "abelha marrom" Ptilotrigona lurida (Smith), da familia Apidae, que por seus movimentos parece exercer efetivamente a função de polinizadora.

\section{AGRADECIMENTOS}

Agradecemos ao Dr. Warwick E. Kerr atual diretor do INPA, e ao Sr. João Camargo do Departamento de Genética, da Fac. Medicina de Ribeirão Preto, por meio dos quasis obti- vemos as identiiicações das abelhas referidas; à Drá. Barbara Carrol orientadora do curso de Entomologia Botânica, pela assistência técnica durante a elaboração deste trabalho; à Profa. Lindalva $P$. de Albuquerque pelo auxílio na identificação de alguns insetos e preparação do material entomológico para estudo, e ao $\mathrm{Sr}$. Osmarino P. Monteiro pela captura das abelhas encontradas.

\section{SUMMARY}

The high commercial value of "cupuaçı" Theo. broma grandiflorum (Willd. ex Spreng.) Schum. (Sterculiaceae), and its native occurrence in Amazonian led us to make some observations on the insects which are eating the leaves and flowers of this plant. Some observations about its pollination are given, and very probably Ptilotrigona lurida (Smith) is responsible by it.

The results are presented in Tables -1 and 2, and some aspects of the attack of flowers by bees is shown in Fig. 1.

\section{BIBLIOGRAFIA CITADA}

Clatrecasas, $\mathbf{J}$.

1964 - Cacao and its allies. A taxonomic revision of the genus Theobroma. Contr. from United States National Herbarium $5(6)$, end of volume; Simitsonian Institution, Washington, D.C. : 614 . 